\title{
Phytochemical profiles, antioxidant and antimicrobial activities of three Potentilla species
}

\author{
Shan-Shan Wang, Dong-Mei Wang*, Wen-Jun Pu and Deng-Wu Li
}

\begin{abstract}
Background: Extracts from Potentilla species have been applied in traditional medicine and exhibit antioxidant, hypoglycemic, anti-inflammatory, antitumor and anti-ulcerogenic properties, but little has been known about the diversity of phytochemistry and pharmacology on this genus. This study investigated and compared the phytochemical profiles, antioxidant and antimicrobial activities of leaf extracts from three Potentilla species (Potentilla fruticosa, Potentilla glabra and Potentilla parvifolia) in order to discover new resources for lead structures and pharmaceutical products.

Methods: Chemical composition and content of six phenolic compounds were evaluated and determined by RP-HPLC; Total phenolic and total flavonoid content were determined using Folin-Ciocalteau colourimetric method and sodium borohydride/chloranil-based method (SBC); Antioxidant activities were determined using DPPH, ABTS and FRAP assays; Antimicrobial properties were investigated by agar dilution and mycelial growth rate method.
\end{abstract}

Results: The results showed hyperoside was the predominant phenolic compound in three Potentilla species by RP-HPLC assay, with the content of 8.86 (P. fruticosa), 2.56 (P. glabra) and $2.68 \mathrm{mg} / \mathrm{g}$ (P. parvifolia), respectively. The highest content of total identified phenolic compounds (hyperoside, (+)-catechin, caffeic acid, ferulic acid, rutin and ellagic acid) was observed in P. parvifolia (14.17 mg/g), follow by P. fruticosa (10.01 mg/g) and P. glabra (7.01 mg/g). P. fruticosa possessed the highest content of total phenolic $(84.93 \pm 0.50 \mathrm{mmol}$ gallic acid equivalent/100 g) and total flavonoid $(84.14 \pm 0.03$ mmol quercetin equivalent/100 g), which were in good correlation with its significant DPPH IC50 $(16.87 \mu \mathrm{g} / \mathrm{mL})$, ABTS (2763.48 $\mu \mathrm{mol}$ Trolox equivalent/g) and FRAP (1398.70 $\mu \mathrm{mol}$ Trolox equivalent/g) capacities. Furthermore, the effective methodology to distinguish the different species of Potentilla was also established by chromatographic fingerprint analysis for the first time. The results of antimicrobial activities showed $P$. fruticosa exhibited the strongest inhibition aganist Gram-positive bacteria, Pseudomonas aeruginosa and Candida albicans with MIC values of $0.78-6.25 \mathrm{mg} / \mathrm{mL}$. P. parvifolia possessed antibacterial and antifungal activities against all the microorganisms tested, with $\mathrm{EC}_{50}$ and MIC values of 20.52-47.02 $\mathrm{mg} / \mathrm{mL}$ and $0.78-50 \mathrm{mg} / \mathrm{mL}$, respectively.

Conclusions: These results indicated that leaf extracts from three Potentilla species could become useful supplement for pharmaceutical products as a new antioxidant and antimicrobial agents.

Keywords: Potentilla spp, Phytochemicals, Antioxidant activity, Antimicrobial activity, RP-HPLC

\section{Background}

The genus Potentilla is a member of the family Rosaceae, which is mainly distributed in temperate, arctic and alpine zones of the Northern hemisphere. This genus has been known since ancient times for their decorative value and curative properties [1]. Extracts from the aerial and/or underground parts have been applied in traditional medicine and exhibit antioxidant, hypoglycemic, anti-inflammatory, antitumor and antiulcerogenic properties [2-6]. Potentilla extracts are

\footnotetext{
* Correspondence: dmwli@163.com

College of Forestry, Northwest A \& F University, Yangling, Shannxi 712100, China
}

preseumed to be safe and no toxic effects when applied to human [7,8]. In Tibet, Potentilla anserina root extracts have been applied for the treatment of certain viral infections as folk medicinal herbs [9]. Similarly the same or other Potentilla species have been used in traditional medicine of different cultures in Europe and Northern America [10]. Most of the biological effects of Potentilla species can be explained by the high amount of hydrolysable and condensed tannins, flavonoids and triterpenes present in all plant parts. Several of the polyphenols are identified as ellagic acid and flavonols glycosylated derivatives [11]. 
P. fruticosa is a species of hardy deciduous flowering shrub in the Potentilla genus of the family Rosaceae, native to the cool temperate and subarctic regions of the northern hemisphere, often growing at high altitudes in mountains [12]. In China, P. fruticosa also called "Jinlaomei" and "Gesanghua", its altitude ranges from 400 to $5000 \mathrm{~m}$ [13]. Apart from its common gardening applications, it also has numerous medicinal virtues [14]. Extracts of $P$. fruticosa have been shown to possess relatively high concentrations of phenolic acids and flavonoids and powerful radical scavenging capacity $[8,15]$. The activity of some extracts was higher than that of the synthetic antioxidant BHT and of extracts isolated from sage (Salvia officinalis), which contains powerful antioxidants [5]. Moreover the leaves of $P$. fruticosa have applications as food additives and an ingredient in cosmetic products [16].

P. glabra is a small shrub species now occurring widely on the Himalayas and neighbor regions. It can reach the highest altitude of $5000 \mathrm{~m}$, indicating its high capability for cold endurance [17]. Differentiations between P. glabra and P. fruticosa are quite subtle, and can only be distinguished by the color of the petals (white versus yellow) [18]. P. parvifolia is another species belonged to the genus Potentilla. Widely distributed in Qinghai, Gansu, Inner Mongolia, Heilongjiang, Tibet and Sichuan in China, which can grow normally at an altitude of 1500 to $4500 \mathrm{~m}$ area. P. glabra and P. parvifolia are also referred to varietas of $P$. fruticosa [19], for the taxonomic status of the shrubby Potentilla is uncertain [12]. To our knowledge, the research of the phytochemicals and antioxidant properties for them are poorly investigated. As most of the biological activities of plant extracts can be explained by their high content of polyphenol [20,21], these two species may also become important sources for medicinal remedies as an alternative to chemical drugs, e.g. in antimicrobial therapy.

Potentilla species have been widely used for a long time in China as folk medicinal herbs and functional tea to treat diarrhoea, hepatitis, rheuma and scabies, but little has been known about the diversity of phytochemistry and pharmacology on this genus. Therefore, a comparison of the different Potentilla species would be desirable in order to discover the diversity of chemical constituents and quantities. In addition, the different types (or regions) of extracts and their phytochemical profiles should be investigated. This would be of high value in order to answer the question whether the phytochemical and pharmacological results for one Potentilla species can be transferred to another Potentilla species and also for one extracts within the same Potentilla species to another kind of extracts. Additionally, the genus Potentilla is abundant in polyphenolics which we detected might be introduced as chemotaxonomic markers of the different Potentilla species.
The objectives for this study were: (1) to determine the content of six phenolic compounds, total phenolics and total flavonoids in three selected Potentilla species; (2) To compare and screen the chemical composition of three Potentilla species by RP-HPLC assay; (3) to measure the antioxidant activity in vitro and (4) to determine the antimicrobial activity of three Potentilla species in vitro.

\section{Methods}

\section{Plant material}

Three samples were collected from different areas (Table 1) and identified by the Herbarium of the Northwest Sci-Tech University of Agriculture and Forestry. Collected plant materials were air-dried under shade at room temperature and were stored at $-20^{\circ} \mathrm{C}$ and protected from light until further analysis.

\section{Chemicals}

Folin-Ciocalteu Reagent (Shanghai solarbio Bioscience \& Technology Co., LTD, PR China); 1,1-diphenyl-2-picrylhydrazyl (DPPH), 2,2-azino-bis(3-ethyl-benzothiazoline6-sulphonic acid) di-ammonium salt (ABTS), 2, 4, 6-Tripyridyl-s-triazine (TPTZ), 6-Hydroxy-2,5,7,8-tetramethylchroman-2-carboxylic Acid (Trolox) (SigmaAldrich Co., St. Louis, USA); Gallic acid monohydrate (Kebang Bioscience \& Technology Co., LTD, PR China); ethanol, acetone (Chengdu Kelong Chemical Co., Ltd, PR China); sodium borohydride $\left(\mathrm{NaBH}_{4}\right)$, methanol, aluminum chloride, acetic acid, hydrochloric acid, vanillin, sodium dihydrogen phosphate, disodium hydrogen phosphate, sodium chloride, potassium chloride, potassium dihydrogen phosphate, sodium carbonate, sodium acetate, ferric trichloride hexahydrate $\left(\mathrm{FeCl}_{3} \cdot 6 \mathrm{H}_{2} \mathrm{O}\right)$, methanol, potassium persulfate (Tianjin Bodi Chemical Co., Ltd, PR China); chloranil(Aladdin Industrial Co., Ltd, PR China); Tetrahydrofuran(THF) (Shenzhen Guanghua technology Co., Ltd, PR China); (+)-catechin, caffeic acid, ferulic acid, hyperoside, rutin, ellagic acid (Yuanye Industrial Co. Ltd, PR China). All other reagents and solvents used were of analytical grade. Deionized water $(18 \mathrm{M} \Omega \mathrm{cm})$ was used to prepare aqueous solutions.

\section{Preparation of the extracts}

The air-dried and powdered sample (2 g) was extracted with $50 \mathrm{~mL}$ of $80 \%$ chilled acetone at $4^{\circ} \mathrm{C}$ for $1 \mathrm{~h}$ and

Table 1 Species from different sources

\begin{tabular}{ccc}
\hline Species & Collected location & Part \\
\hline P. fruticosa & Huzhu Northern Mountain, Qinghai & Leaf \\
P. glabra & Helan Mountain, Ningxia & Leaf \\
P. parvifolia & Taibai Mountain, Shaanxi & Leaf \\
\hline
\end{tabular}


then the mixture was filtered with vacuum pump. Extracts were transferred into a new test tube. The residues were extracted with additional $50 \mathrm{~mL} 80 \%$ chilled acetone twice using the same conditions. Extracts in the new test tube were evaporated to dryness at $45^{\circ} \mathrm{C}$ with rotary evaporators, the dry residue was dissolved in volumetric flask with methanol and stored at $-20^{\circ} \mathrm{C}$ in the dark for further use. It can be diluted if necessary. All extractions were performed in triplicate.

\section{Determination of total phenolic content}

The total phenolic content was determined using the Folin-Ciocalteau colourimetric method with some modification [22]. Samples were thawed and prepared at concentration of $0.2 \mathrm{mg} / \mathrm{mL}$. Add $100 \mu \mathrm{L}$ sample and $400 \mu \mathrm{L}$ deionized water to glass culture tube. Add $100 \mu \mathrm{L}$ Folin-Ciocalteu Reagent, mix well and let the samples stand for 6 minutes. Add $1 \mathrm{~mL} \mathrm{7 \%} \mathrm{sodium} \mathrm{car-}$ bonate and $0.8 \mathrm{~mL}$ deionized water, mix and let stand for 90 minutes at room temperature and its absorbance was read at $517 \mathrm{~nm}$ with a spectrophotometer (Shimadzu UV-1800). The phenolic content was calculated as Gallic acid equivalent from the calibration curve of Gallic acid standard solutions (20-300 $\mu \mathrm{g} / \mathrm{mL})$ and was expressed as millimole Gallic acid equivalent per $100 \mathrm{~g}$ of dry weight (mmol equiv.GAE/100 g). Data were reported as mean \pm SD for three replicates.

\section{Determination of total flavonoids content}

The total flavonoid content was determined using the sodium borohydride/chloranil-based (SBC) assay [23]. Samples were thawed and prepared at concentration of $0.2 \mathrm{mg} / \mathrm{mL}$. Then dried to dryness and reconstituted in $1 \mathrm{~mL}$ of THF/EtOH $(1: 1, \mathrm{v} / \mathrm{v})$. Quercetin standards (0.1$10.0 \mathrm{mM}$ ) were prepared fresh each day before use in $1 \mathrm{~mL}$ of THF/EtOH (1:1, v/v). Each test tube with $1 \mathrm{~mL}$ of sample solution or $1 \mathrm{~mL}$ of quercetin standard solution had $0.5 \mathrm{~mL}$ of $50 \mathrm{mM} \mathrm{NaBH}_{4}$ solution and $0.5 \mathrm{~mL}$ of $74.56 \mathrm{mM} \mathrm{AlCl}$ solution added. The tubes were shaken in a thermo shaker at room temperature for $30 \mathrm{~min}$ on setting 400. An additional $0.5 \mathrm{~mL}$ of $50.0 \mathrm{mM}$ $\mathrm{NaBH}_{4}$ solution was added into each test tube with continuing shaking for another $30 \mathrm{~min}$ at room temperature. $2.0 \mathrm{~mL}$ of $0.8 \mathrm{M}$ cold acetic acid solution $\left(4^{\circ} \mathrm{C}\right)$ was added to each test tube, and the solutions were protected from the light for $15 \mathrm{~min}$ after a thorough mix. Then $1 \mathrm{~mL}$ of $20.0 \mathrm{mM}$ chloranil was added into each tube. The tubes were placed in the dry bath incubator set at $95^{\circ} \mathrm{C}$ with shaking for $60 \mathrm{~min}$ in an orbital shaker. And then the reaction solutions were cooled using tap water, and the final volume was brought to $4 \mathrm{~mL}$ with methanol. $1 \mathrm{~mL} 16 \%$ vanillin methanol solution was added to each tube, mixing well. Then $2 \mathrm{~mL}$ of $12 \mathrm{M}$ concentrated $\mathrm{HCl}$ was added to each tube and kept in dark at room temperature for $15 \mathrm{~min}$ after a thorough mix. Then the absorbance was measured at $490 \mathrm{~nm}$ using spectrophotometer. Data were reported as mean \pm SD for three replicates. Total flavonoid content were expressed as millimole quercetin equivalents per $100 \mathrm{~g}$ of dry weight (mmol equiv. QUE/100 g).

\section{Reverse-phase HPLC analysis of six phenolic compounds}

Stock solution was thawed and then analysed by RPHPLC. The content of six phenolic compounds $((+)-$ catechin, caffeic acid, ferulic acid, hyperoside, rutin and ellagic acid) were quantified by using an Agilent Technologies 1260 series liquid chromatograph (RP-HPLC) coupled with a variable wavelength detector. The quantification was carried out on a SB- $\mathrm{C}_{18}$ reversed phase column (5 $\left.\mu \mathrm{m}, 4.6^{*} 250 \mathrm{~mm}\right)$ at ambient temperature. The mobile phase consisted of water with $0.2 \%$ trifluoroacetic acid (solvent A) and methanol with $0.2 \%$ trifluoroacetic acid (solvent B). The following gradient elution program was run: $5 \% \mathrm{~B}(0 \mathrm{~min}), 20 \% \mathrm{~B}$ (0-10 $\mathrm{min}), 25 \% \mathrm{~B}$ (10-15 $\mathrm{min}), 25 \% \mathrm{~B}$ (15-20 $\mathrm{min})$, $30 \%$ B (20-25 min), 30\% $\mathrm{B}(25-35 \mathrm{~min}), 35 \% \quad \mathrm{~B}$ (35-40 min) , 45\% B (40-50 min) , 100\% B (50-60 min), $100 \% \mathrm{~B}$ (60-65 min). The mobile phase flow rate was kept at $0.8 \mathrm{ml} / \mathrm{min}$. The injection volume was $20 \mu \mathrm{L}$, and the chromatogram was recorded at $320 \mathrm{~nm}$ and $360 \mathrm{~nm}$. Analyses were performed in triplicate.

\section{In vitro antioxidant activity}

\section{DPPH free radical-scavenging assay}

The scavenging effects of samples for DPPH radical were monitored according to the method of Yen [24]. Samples were diluted in ethanol at the following concentrations: $400,200,100,50,25,12.5,6.25$ and $3.125 \mu \mathrm{g} / \mathrm{mL}$. Briefly, a $2.0 \mathrm{~mL}$ of test sample was added to $2.0 \mathrm{~mL}$ of $0.1 \mathrm{mM}$ DPPH methanolic solution. The mixture was mixed well and then left to stand in the dark for $30 \mathrm{~min}$ at room temperature, and its absorbance was read at $517 \mathrm{~nm}$ with a spectrophotometer against a blank. Trolox in the same concentrations was used as the positive control. All measurements were done in triplicate. DPPH free radical-scavenging activity was calculated according to the following equation:

$$
\text { Inhibition rate } \left.(\%)=\left[1-\left(\mathrm{A}_{\mathrm{i}}-\mathrm{A}_{\mathrm{j}}\right) / \mathrm{A}_{0}\right)\right] * 100
$$

Where $A_{0}$ was the absorbance of methanol $(2 \mathrm{ml})$ and DPPH $(2 \mathrm{ml}), \mathrm{A}_{\mathrm{i}}$ was the absorbance of the tested sample $(2 \mathrm{ml}$ sample and $2 \mathrm{ml} \mathrm{DPPH})$, and $\mathrm{A}_{\mathrm{j}}$ was the absorbance of the blank ( $2 \mathrm{ml}$ sample and $2 \mathrm{ml}$ methanol).

A lower absorbance of the reaction mixture indicated a higher $\mathrm{DPPH}$ radical-scavenging activity. $\mathrm{IC}_{50}$ values were the effective concentrations at which DPPH 
radicals were scavenged by $50 \%$, and were obtained from linear regression analysis.

\section{ABTS. ${ }^{+}$radical cation scavenging assay}

The method of decolourisation of free radical ABTS ${ }^{+}$was performed according to Re et al. with some modification [25]. The ABTS ${ }^{+}$was prepared by mixing an ABTS stock solution (7 mM in water) with $2.45 \mathrm{mM}$ potassium persulfate. This mixture was allowed to stand for $12-16 \mathrm{~h}$ at room temperature in the dark until reaching a stable oxidative state. For each analysis, the ABTS $\bullet^{+}$solution was diluted with $\mathrm{pH}$ 7.4 phosphate buffered saline (PBS) solution to an initial absorbance of $0.700 \pm 0.021$ at $734 \mathrm{~nm}$. This solution was freshly prepared for each analysis. For the spectrophotometric assay, $100 \mu \mathrm{L}$ extracts with a concentration $(\mathrm{w} / \mathrm{v})$ of $0.2 \mathrm{mg} / \mathrm{mL}$ was added to $3.9 \mathrm{~mL}$ of $\mathrm{ABTS}^{+}{ }^{+}$solution and the absorbance was determined at $734 \mathrm{~nm}$. Results were expressed in terms of micromoles trolox equivalent per $g$ of dry weight ( $\mu \mathrm{mol}$ eq. trolox/g). All determinations were carried out in triplicate.

\section{Ferric reducing power (FRAP) assay}

The method of FRAP assay used was a modified version of that reported by Benzie and Strain [26]. The method is based on the reduction of a colorless ferric complex 2 , 4, 6-tripyridyl-s-triazine complex $\left(\mathrm{Fe}^{3+}\right.$-tripyridyltriazine) to a blue-colored ferrous form $\left(\mathrm{Fe}^{2+}\right.$-tripyridyltriazine) by the action of electron-donating antioxidants. The FRAP reagent included $300 \mathrm{mM}$ acetate buffer (3.1 g $\mathrm{C}_{2} \mathrm{H}_{3} \mathrm{NaO}_{2} \cdot 3 \mathrm{H}_{2} \mathrm{O}$ and $1.6 \mathrm{~mL} \mathrm{C}_{2} \mathrm{H}_{4} \mathrm{O}_{2}$ ), $10 \mathrm{mM}$ TPTZ solution in $40 \mathrm{mM} \mathrm{HCl}$ and $20 \mathrm{mM} \mathrm{FeCl}_{3} \cdot 6 \mathrm{H}_{2} \mathrm{O}$ solution, with the ratio of $10: 1: 1(\mathrm{v} / \mathrm{v})$. The extracts were prepared at a final concentration of $0.2 \mathrm{mg} / \mathrm{mL}$. For each analysis, $400 \mu \mathrm{L}$ of sample solutions was added to $3 \mathrm{~mL}$ of freshly prepared FRAP reagent. The reaction mixture was incubated for $30 \mathrm{~min}$ at $37^{\circ} \mathrm{C}$ in a water bath in the dark. Then, the absorbance of the samples was measured at $593 \mathrm{~nm}$ using the spectrophotometer. The trolox was used as the standard solution. The FRAP results were expressed in terms of micromoles trolox equivalent per $\mathrm{g}$ of dry weight ( $\mu \mathrm{mol}$ eq. trolox/g). All of the treatment groups were measured in triplicate.

\section{In vitro antimicrobial activity \\ Preparation of test solution}

Each of the finely powdered samples (5 g) was extracted with $125 \mathrm{~mL}$ of $80 \%$ chilled acetone at $4^{\circ} \mathrm{C}$ for $1 \mathrm{~h}$ and then the mixture was filtered with vacuum. Extracts were transferred into a new test tube. The residues were extracted with one additional $125 \mathrm{~mL} \mathrm{80 \%} \mathrm{chilled} \mathrm{acet-}$ one twice using the same conditions. Extracts in the new test tube were transferred into $50 \mathrm{~mL}$ volumetric flask with $80 \%$ acetone. It can be diluted if necessary. All extractions were performed in triplicate.

\section{Microorganisms}

Six bacterial strains and one fungal strain were procured from Microbial Culture Collection Center of Guangdong Institute of Microbiology, China. The strains used are Staphylococcus aureus (ATCC No. 6538), Enterococcus faecalis (ATCC No. 29212), Bacillus subtilis (ATCC No. 6633), Escherichia coli (ATCC No. 25922), Klebsiella pneumoniae (CMCC No. 46117), Pseudomonas aeruginosa (ATCC No. 27853) and Candida albicans (ATCC No. 10231).

Twenty test fungi species, Alternaria alternata, Alternaria brassicae, Alternaria solani, Bipolaris sorokininan, Botrytis cinerrea, Cladosporium fulvum, Colletotrichum gloeosporioides, Verticillium dahliae, Dothiorella gregaria, Fusarium oxysporum, Glomerella cingnlata, Phacidiopycnis washingtonensis, Physalospora piricola, Piricularia oryzae, Rhizoctonia cerealis, Sclerotinia sclerotiorum, Thanatephorus cucumeris, Valsa mali, Venturia pyrina and Verticillium dahliae were kindly provided by the College of Resources and Environment, Northwest A\&F University, Yangling, China.

\section{Minimum inhibitory concentration (MIC)}

The minimal inhibitory concentration (MIC) of extracts for antimicrobial testing was determined by agar dilution method according to that approved by the National Committee for Clinical Laboratory Standards (NCCLS) with some modification [27]: a series of two fold dilutions of each extracts, ranging from 0.2 to $100 \mathrm{mg} / \mathrm{ml}$, was prepared. Each of the test sterile petri dishes contained $9 \mathrm{ml}$ of medium and $1 \mathrm{ml}$ extracts of three Potentilla species, the solvent without extracts served as negative control and using benzylpenicillin as a positive control. The medium was inoculated with $3 \mu \mathrm{l}$ aliquots of culture containing approximately $10^{5} \mathrm{CFU} / \mathrm{ml}$ of each organism. The bacterial strains were cultured on Mueller-Hinton agar (MHA) medium at $37^{\circ} \mathrm{C}$ for $24 \mathrm{~h}$ and fungal strains on potato dextrose agar (PDA) medium at $28^{\circ} \mathrm{C}$ for $48 \mathrm{~h}$. Inhibition of organism growth in the plates containing test crude extracts was judged by comparison with growth in blank control plates. The MIC values were determined as the lowest concentration of extracts inhibiting visible growth of each organism on the agar plate.

\section{Antifungal activities against plant pathogenic fungi}

Mycelial growth rate method was conducted to evaluate antifungal activity of phytochemicals against plant pathogenic fungi $[28,29]$. The 20 test fungi were seeded on sterilized potato dextrose agar (PDA) media in petri dishes. Each of the test PDA sterile petri dishes contained $9 \mathrm{ml}$ of molten medium and $1 \mathrm{ml}$ extracts of three Potentilla species (with concentration of $50 \mathrm{mg} / \mathrm{ml}$ ), the solvent without extracts served as negative control. 
The plates were then incubated at $28^{\circ} \mathrm{C}$ for $72 \mathrm{~h}$. Zones of inhibition were measured and recorded. The percentage inhibition was calculated:

$$
\left[\left(\text { Diameter }_{\text {Control }}-\text { Diameter }_{\text {Test }}\right) / \text { Diameter }_{\text {Control }}\right] * 100
$$

By this procedure, five pathogenic fungi, with inhibition percentage over 50\%, were chosen for further analysis.

Various extracts of three Potentilla species were tested separately for kinetic study and evaluation of antifungal activity of five selected fungi, including Alternaria alternata, Alternaria brassicae, Glomerella cingnlata, Physalospora piricola and Venturia pyrina. Each extracts solutions were serially diluted by the two-fold serial dilution method and added to PDA with final concentrations ranging from 6.25 to $100 \mathrm{mg} / \mathrm{ml}$. Amphotericin disks were used as standard. And the concentration of the sample required for $50 \%$ inhibition rate $\left(\mathrm{EC}_{50}\right)$ was calculated using linear regression analysis. The experiment was repeated thrice and the average values were calculated.

\section{Statistical analysis}

All results were expressed as the mean \pm standard deviation (SD). The significant difference was calculated by SPSS one-way ANOVA followed by Duncan's test; values $<0.05$ were considered to be significant.

\section{Results and discussion}

\section{Total phenolic and flavonoid content}

Total phenolic content of three leaf extracts are presented in Table 2. Significant difference was found among three leaf extracts $(\mathrm{p}<0.05)$. The results showed that $P$. fruticosa had the highest total phenolic content $(84.93 \pm 0.50 \mathrm{mmol}$ equiv. GAE/100 g), followed by P. glabra $(69.21 \pm 0.64 \mathrm{mmol}$ equiv. GAE/100 g) and $P$. parvifolia $(55.22 \pm 0.75 \mathrm{mmol}$ equiv. GAE/100 g). Tomczyk reported that $P$. fruticosa which obtained from the Hortus Botanicus Universitatis Masarykianae had high concentrations of total polyphenols (116.30 \pm $3.90 \mathrm{mg}$ GAE/g) [8]. In this work, the total phenolic content of $P$. fruticosa was higher than that had been

Table 2 Contents of total phenolic and flavonoids of leaf extracts of three Potentilla species

\begin{tabular}{lcc}
\hline Species & $\begin{array}{c}\text { Total phenolic content } \\
\text { (mmol equiv. GAE/100 g) }\end{array}$ & $\begin{array}{c}\text { Total flavonoid content } \\
\text { (mmol equiv. QUE/100 g) }\end{array}$ \\
\hline P. fruticosa & $84.93 \pm 0.50^{\mathrm{c}}$ & $84.14 \pm 0.03^{\mathrm{c}}$ \\
P. glabra & $69.21 \pm 0.64^{\mathrm{b}}$ & $72.76 \pm 0.02^{\mathrm{b}}$ \\
P. parvifolia & $55.22 \pm 0.75^{\mathrm{a}}$ & $41.87 \pm 0.04^{\mathrm{a}}$ \\
\hline
\end{tabular}

mmol equiv. GAE/100 g: millimole gallic acid equivalent per $100 \mathrm{gram}$ mmol equiv. QUE/100 g: millimole quercetin equivalent per $100 \mathrm{gram}$.

Each values represented in tables are means $\pm \mathrm{SD}(\mathrm{N}=3)$

Values with different letters $(a, b, c)$ within same column are significantly different $(\mathrm{P}<0.05)$. reported by Tomczyk. Since all samples were collected from different places of origin, these differences may be due to diversity in biological (species, organ and developmental stage) and environmental factors [30].

Total flavonoids content of three Potentilla leaf extracts were measured (Table 2). P. fruticosa presented the highest flavonoid content $(84.14 \pm 0.03 \mathrm{mmol}$ equiv. QUE/100 g), followed by P. glabra $(72.76 \pm 0.02 \mathrm{mmol}$ equiv. QUE/100 g) and P. parvifolia $(41.87 \pm 0.04 \mathrm{mmol}$ equiv. QUE/100 g). The flavonoid content of three leaf extracts were significantly difference from each other $(\mathrm{p}<0.05)$. It is well known that both genetic and environmental factors play important roles on flavonoid composition and nutritional quality of plants. Therefore, these factors would be the key point for affecting the flavonoid content of three Potentilla species.

Tomczyk had found that $P$. fruticosa had high content of total flavonoid $(7.0 \pm 1.1 \mathrm{mg}$ QUE $/ \mathrm{g})$ for the aerial parts [8]. This value was significantly lower than that reported in the present study. Due to we adopted the sodium borohydride/chloranil-based (SBC) assay to detect the total flavonoids, which can measure all types of flavonoids, including flavones, flavonols, flavonones, flavononols, isoflavonoids, flavanols, and anthocyanins [23]. Thereby the significant differences found between those values may arise from the use of two different analytical methods.

\section{HPLC analysis of three Potentilla species Validation of the method}

Under the optimal conditions, six phenolic compounds in three leaf extracts were detected and well separated. The precision of the analytical method was determined by assaying six replicate of compounds 4, 7, 10, 13, 14 and 16 (Figure 1), the relative standard deviation (RSD) of the peak area were estimated to be $0.73-2.11 \%$ $(\mathrm{N}=6)$. The repeatability of the method was detected by extracting one sample ( $P$. fruticosa) for six times, while the area of the peaks were recorded, the RSD of the area varied from $0.65 \%$ to $3.28 \%(\mathrm{~N}=6)$. A recovery experiment was performed to confirm the accuracy of the method by mixing quantified samples with standard compounds to appropriate amount. The average percentages of recovery of six phenolic compounds were at different levels and ranged from $94.81 \pm 0.66 \%$ to 105.95 $\pm 2.44 \%$ and RSD varied from $0.36 \%$ to $2.88 \%(\mathrm{~N}=6)$. The stability of compounds 4, 7, 10,13, 14 and 16 (Figure 1) in the sample solution were evaluated by determining their relative peak areas after storage at room temperature for $2,4,8,16$ and $24 \mathrm{~h}$, respectively, the RSD of the relative peak areas were less than $3 \%$. All results were summarized in Table 3 and demonstrated that the conditions for the analysis were repeatable and accurate. 


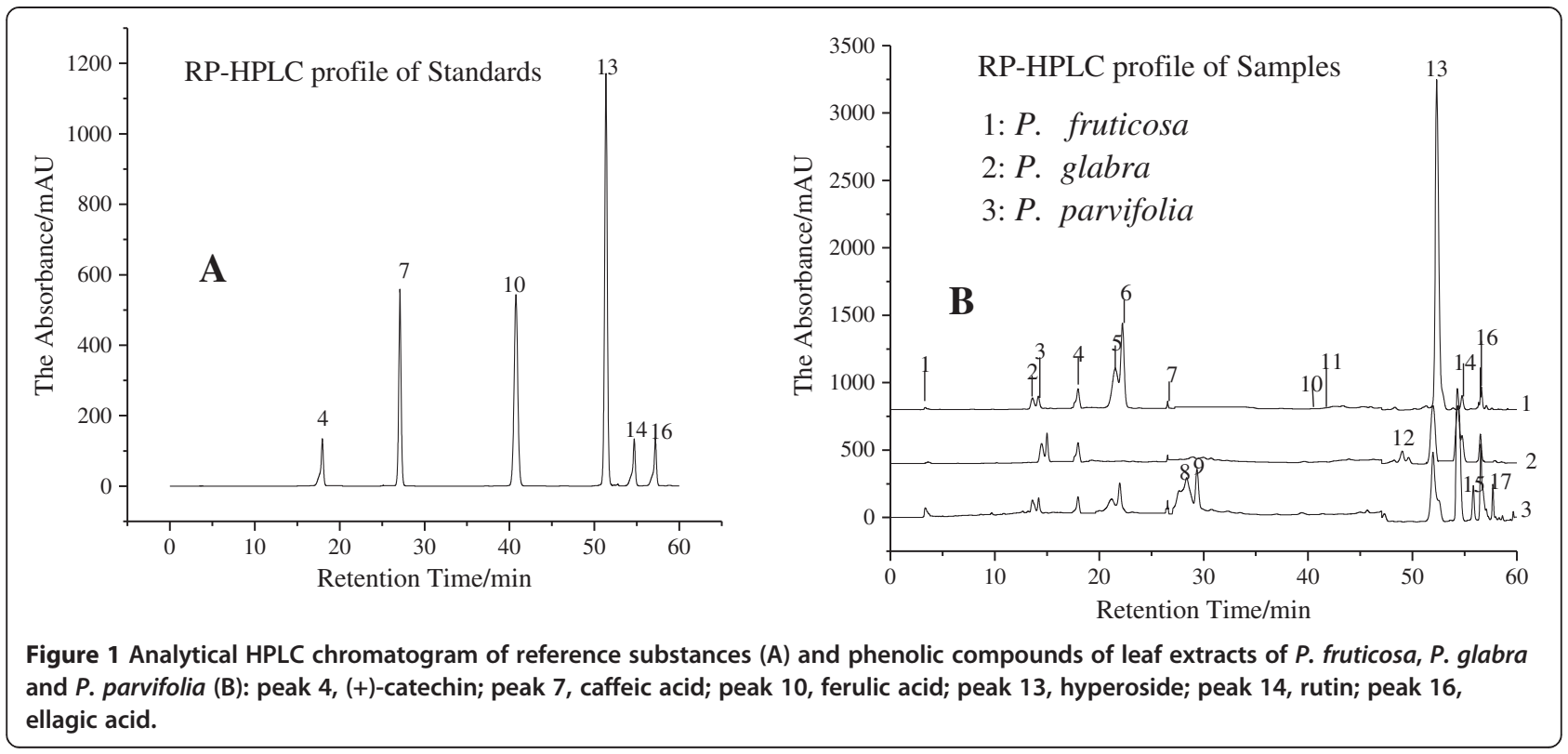

\section{Content of six phenolic compounds}

Chromatograms of leaf extracts of three Potentilla species were analyzed by HPLC method. Seventeen peaks shown in the chromatograms were assigned as characteristic peaks. Based on comparison of the UV spectra and retention time of sample peaks to those of the standards, peaks $4,7,10,13,14$ and 16 were identified as (+)-catechin, caffeic acid, ferulic acid, hyperoside, rutin and ellagic acid (Figure 1). Content of hyperoside was significantly high in extracts of three Potentilla species, especially in the extracts of $P$. fruticosa $(8.86 \pm 0.08$ $\mathrm{mg} / \mathrm{g})$. Meanwhile, $(+)$-catechin, rutin and ellagic acid were the most abundant in the extracts of $P$. parvifolia, with the content of $2.53 \pm 0.37,4.11 \pm 0.07$ and $4.33 \pm$ $0.09 \mathrm{mg} / \mathrm{g}$, respectively. In addition, the content of caffeic acid $(0.19 \pm 0.00$ to $0.51 \pm 0.02 \mathrm{mg} / \mathrm{g})$ and ferulic acid $(0.01 \pm 0.00$ to $0.02 \pm 0.00 \mathrm{mg} / \mathrm{g})$ were relatively lower and not significantly different $(\mathrm{p}>0.05)$ among three Potentilla leaf extracts. The content of total identified compounds varied significantly among three leaf extracts $(\mathrm{p}<0.05)$. The highest was observed in the leaf extracts of $P$. parvifolia $(14.17 \mathrm{mg} / \mathrm{g})$, follow by $P$. fruticosa $(10.01 \mathrm{mg} / \mathrm{g})$ and $P$. glabra $(7.01 \mathrm{mg} / \mathrm{g})$. The results are summarized in Table 4.

\section{Chemical composition of three Potentilla species}

The HPLC chromatograms of three Potentilla leaf extracts were shown in Figure 1b. Extracts of $P$. parvifolia possessed the richest peak numbers, followed by $P$. glabra and P. fruticosa. In detail, the peaks $1,2,3,4((+)-$ catechin), 5, 6, 7 (caffeic acid), 10 (ferulic acid), 13 (hyperoside), 14 (rutin) and 16 (ellagic acid) were common peaks which were detected in all leaf extracts. Meanwhile, the content of peak 13 (hyperoside) was significantly higher in P. fruticosa. Peaks 4((+)-catechin), 14(rutin) and 16(ellagic acid) were the most abundant in P. parvifolia. However, peak 12 was only detected in P. glabra. Peaks 8, 9, 15, 17 were absent in $P$. fruticosa and P. glabra, but were found in $P$. parvifolia. In addition, peak 11 was typical in the extracts of $P$. fruticosa and P. glabra.

In total, this analysis of chromatograms provides a highly rational approach to the authentication and

Table 3 Method validation for the quantitative determination of six phenolic compounds using RP-HPLC

\begin{tabular}{|c|c|c|c|c|c|c|c|c|}
\hline \multirow{2}{*}{$\begin{array}{c}\text { Peak } \\
\text { no. }\end{array}$} & \multirow[t]{2}{*}{ Compounds } & \multirow[t]{2}{*}{ Regression equation } & \multicolumn{2}{|c|}{ Precision experiment } & \multicolumn{2}{|c|}{ Repeatability } & \multicolumn{2}{|l|}{ Recovery experiment } \\
\hline & & & Area of peak & RSD (\%) & Area of peak & RSD (\%) & Average recovery rate (\%) & RSD (\%) \\
\hline 4 & (+)-catechin & $y=2004.7 x-25.13\left(R^{2}=0.9973\right)$ & $83.12 \pm 0.61$ & 0.73 & $12.82 \pm 0.22$ & 1.74 & $101.54 \pm 3.08$ & 1.03 \\
\hline 7 & Caffeic acid & $y=146577 x+12.70\left(R^{2}=0.9998\right)$ & $323.05 \pm 1.83$ & 1.32 & $285.04 \pm 2.94$ & 2.94 & $102.66 \pm 2.96$ & 2.88 \\
\hline 10 & Ferulic acid & $y=141714 x-14.70\left(R^{2}=0.9998\right)$ & $416.81 \pm 0.92$ & 1.88 & $32.85 \pm 0.87$ & 1.32 & $105.95 \pm 2.44$ & 2.3 \\
\hline 13 & Hyperoside & $y=66172 x+37.96\left(R^{2}=0.9986\right)$ & $960.32 \pm 5.22$ & 2.11 & $5801.02 \pm 17.51$ & 2.66 & $105.72 \pm 1.56$ & 1.48 \\
\hline 14 & Rutin & $y=43663 x+30.06\left(R^{2}=0.9964\right)$ & $89.79 \pm 0.65$ & 0.76 & $239.68 \pm 7.85$ & 0.65 & $96.21 \pm 0.34$ & 0.36 \\
\hline 16 & Ellagic acid & $y=62654 x-82.44\left(R^{2}=0.9999\right)$ & $101.25 \pm 1.43$ & 0.93 & $181.42 \pm 2.40$ & 3.28 & $102.60 \pm 1.20$ & 1.17 \\
\hline
\end{tabular}

Values were expressed in mean $\pm S D(N=6)$. 
Table 4 Content of phenolic compounds of three Potentilla leaf extracts

\begin{tabular}{|c|c|c|c|c|c|}
\hline \multirow[t]{2}{*}{ Peak No. } & \multirow[t]{2}{*}{ Compounds } & \multirow[t]{2}{*}{ Rentention time(min) } & \multicolumn{3}{|c|}{ Content $(\mathrm{mg} / \mathrm{g})$} \\
\hline & & & $P$. fruticosa & P. glabra & P. parvifolia \\
\hline 4 & $(+)$-catechin & 17.96 & $0.60 \pm 0.03^{a}$ & $0.54 \pm 0.02^{\mathrm{a}}$ & $2.53 \pm 0.37^{b}$ \\
\hline 7 & Caffeic acid & 26.29 & $0.19 \pm 0.00^{\mathrm{a}}$ & $0.33 \pm 0.04^{\mathrm{a}}$ & $0.51 \pm 0.02^{\mathrm{a}}$ \\
\hline 10 & Ferulic acid & 41.34 & $0.02 \pm 0.00^{\mathrm{a}}$ & $0.02 \pm 0.00^{\mathrm{a}}$ & $0.01 \pm 0.00^{\mathrm{a}}$ \\
\hline 13 & Hyperoside & 51.09 & $8.86 \pm 0.08^{c}$ & $2.56 \pm 0.11^{\mathrm{a}}$ & $2.68 \pm 0.05^{b}$ \\
\hline 14 & Rutin & 53.77 & $0.05 \pm 0.00^{\mathrm{a}}$ & $2.56 \pm 0.01^{b}$ & $4.11 \pm 0.07^{c}$ \\
\hline 16 & Ellagic acid & 56.61 & $0.29 \pm 0.01^{a}$ & $1.00 \pm 0.01^{b}$ & $4.33 \pm 0.09^{c}$ \\
\hline Total identified & - & - & $10.01^{b}$ & $7.01^{\mathrm{a}}$ & $14.17^{c}$ \\
\hline
\end{tabular}

Each values represented in tables are means $\pm \mathrm{SD}(\mathrm{N}=3)$.

Values with different letters $(a, b, c)$ within same row are significantly different $(P<0.05)$.

quality assessment of three Potentilla species through these characteristic peaks. And to our knowledge, this is the first report of the effective use of the methodology to distinguish the three different species of Potentilla. Furthermore, the considerable variation in the phytochemical composition of different extracts of Potentilla revealed by our research suggested that the technique reported here can also be used to determine relationships between phytochemical composition and therapeutic effects. Moreover, although this present study relates only to three Potentilla leaf extracts, the method has wider correlation for identifying species and quality assessment of other medicinal plants.

\section{In vitro antioxidant activity}

\section{DPPH free radical scavenging activity}

The results of free radical scavenging properties of three Potentilla leaf extracts were showed in Figure 2 and Table 5. In DPPH assay, all extracts showed a notable radical scavenging activity in a dose-dependent manner within a certain range and were significantly different $(\mathrm{p}<0.05)$. The highest antioxidant activity was obtained from the extracts of $P$. fruticosa with the lowest $\mathrm{IC}_{50}$ value of $16.87 \pm 0.39$ $\mu \mathrm{g} / \mathrm{mL}$, followed by P. glabra $(19.37 \pm 0.64 \mu \mathrm{g} / \mathrm{mL})$ and P. parvifolia $(23.87 \pm 0.20 \mu \mathrm{g} / \mathrm{mL})$.

\section{ABTS. ${ }^{+}$radical cation scavenging activity}

ABTS activity was quantified in terms of percentage inhibition of the ABTS ${ }^{+}$radical cation by antioxidants in each sample. The ABTS values of the three samples were presented in Table 5. The results showed the same order of activity observed in the DPPH method. All extracts showed the capacity to neutralise the radical cation ABTS $^{+}$and showed significant difference at $\mathrm{P}<0.05$. The highest activity was obtained from the $P$. fruticosa extracts with a value of $2763.48 \pm 0.01 \mu$ mol equiv. Trolox/g, followed by $P$. glabra and $P$. parvifolia with values of $2192.16 \pm 8.18$ and $2140.22 \pm 32.71 \mu \mathrm{mol}$ equiv. Trolox/g, respectively.

\section{Ferric reducing power (FRAP) assay}

The FRAP assay evaluates the antioxidant properties of the extracts based on its reducing ability. The values obtained from three leaf extracts (Table 5) were significantly different $(\mathrm{p}<0.05)$, but the order were inconsistent with the DPPH and ABTS assays. In this study,

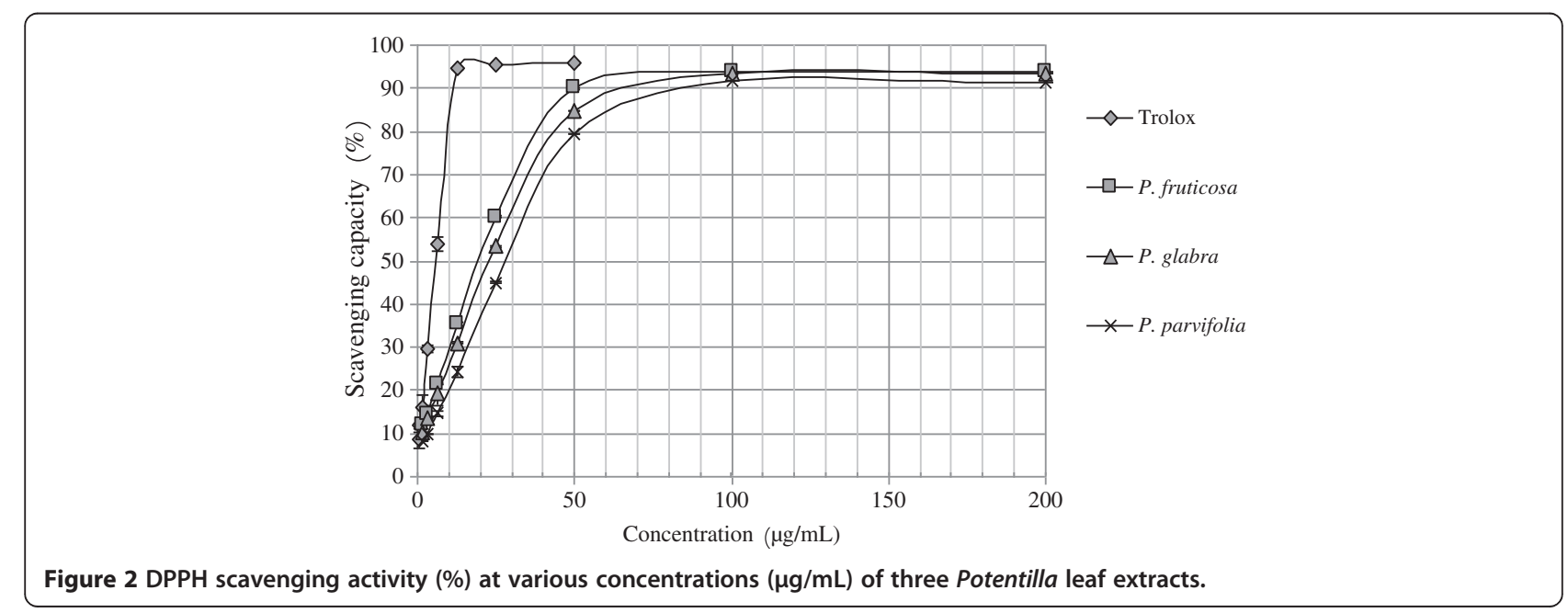


Table 5 Antioxidant activities of three Potentilla leaf extracts

\begin{tabular}{|c|c|c|c|}
\hline Samples & $\begin{array}{c}\mathrm{DPPH}_{\mathrm{IC50}} \\
(\mu \mathrm{g} / \mathrm{mL})\end{array}$ & $\begin{array}{c}\text { ABTS } \\
(\mu \mathrm{mol} \text { Trolox } / \mathrm{g}) \\
\end{array}$ & $\begin{array}{c}\text { FRAP } \\
(\mu \mathrm{mol} \text { Trolox } / \mathrm{g}) \\
\end{array}$ \\
\hline P. fruticosa & $16.87 \pm 0.39^{c}$ & $2763.48 \pm 0.01^{c}$ & $1398.70 \pm 8.29^{c}$ \\
\hline P. glabra & $19.37 \pm 0.64^{b}$ & $2192.16 \pm 8.18^{b}$ & $1142.22 \pm 0.80^{a}$ \\
\hline P. parvifolia & $23.87 \pm 0.20^{\mathrm{a}}$ & $2140.22 \pm 32.71^{a}$ & $1291.76 \pm 0.01^{b}$ \\
\hline Trolox & $4.28 \pm 0.21^{d}$ & - & - \\
\hline
\end{tabular}

Each values represented in tables are means $\pm \mathrm{SD}(\mathrm{N}=3)$.

Values with different letters $(a, b, c, d)$ within same column are significantly different $(P<0.05)$.

extracts of $P$. fruticosa still provided the highest antioxidant capacity with a FRAP value of $1398.70 \pm 8.29 \mu \mathrm{mol}$ equiv. Trolox/g, followed by $P$. parvifolia and P. glabra with values of $1291.76 \pm 0.01$ and $1142.22 \pm 0.80 \mu \mathrm{mol}$ equiv. Trolox/g, respectively.

Based on these results, it is possible to infer that leaf extracts of $P$. fruticosa not only presented the highest free radical scavenge capacity but also the strongest reducing capacity. It is well known that the antioxidant activity of a plant extracts largely depends on both the composition of the extracts and the test system, and cannot be fully evaluated by one single method due to the various mechanisms of antioxidant action, so more research need to be conducted.

\section{Correlations between the total phenolic and flavonoids content and antioxidant activities}

Table 6 showed the correlations (linear regression coefficients, $\mathrm{R}^{2}$ ) between the total phenolic content (TPC), total flavonoids content (TFC) and the three antioxidant assays results for three Potentilla leaf extracts. The DPPH method showed a good correlation with the TPC $\left(R^{2}=0.9617\right)$ and a very good correlation $\left(R^{2}=0.9906\right)$ with the TFC, indicating that most phenolic compounds extracted from three Potentilla leaf extracts were likely to contribute to the radical scavenging activity in this method.

ABTS results were well correlated $\left(R^{2}=0.8376\right)$ to the TPC but poorly with the TFC $\left(\mathrm{R}^{2}=0.5762\right)$. It is known that only flavonoids of a certain structure and particularly hydroxyl position in the molecule determine antioxidant properties, in general these properties depend on the ability to donate hydrogen or electron to a free

Table 6 Correlations values $\left(\mathbf{R}^{2}\right)$ between the antioxidant activities and total phenolic content and total flavonoid content of three Potentilla leaf extracts

\begin{tabular}{ccc}
\hline $\mathbf{R}^{\mathbf{2}}$ & TPC & TFC \\
\hline DPPH & 0.9617 & 0.9906 \\
ABTS & 0.8376 & 0.5762 \\
FRAP & 0.1984 & 0.0278 \\
\hline
\end{tabular}

radical. This structure-activity dependency can be the explanation for the correlation decrease observed.

The FRAP method showed a very poor correlation with the TPC $\left(R^{2}=0.1984\right)$ and the TFC $\left(R^{2}=0.0278\right)$. It may happen that the leaf extracts of some compounds are good radical scavengers but poor reducing agents, thus leading to nonlinear results.

Accordingly, the variation of antioxidant capacity among them could be explained by their phenolic content and composition differences.

\section{Antibacterial and antifungal activities Minimal inhibitory concentration}

MIC values of three extracts are shown in Table 7. Six bacteria and one fungus were tested. The control $(80 \%$ acetone) did not inhibit any of microorganisms tested. Among the plants tested, $P$. fruticosa showed the best activity against the Gram-negative bacteria $(6.25 \mathrm{mg} / \mathrm{ml})$ and Gram-negative bacteria Pseudomonas aeruginosa $(6.25 \mathrm{mg} / \mathrm{ml})$. Poor inhibitory activity was detected against another two Gram-negative bacteria (Escherichia coli and Klebsiella pneumoniae). The antimicrobial effects of $P$. fruticosa were previously studied, the difference is that Tomczyk found P. fruticosa was failed to inhibit the growth of Gram-(-) bacteria [31], but our results showed a higher antibacterial and antifungal activity than that of Tomczyk's. This may be due to the different concentration of the single compounds and other phytochemicals in extracts show significant antimicrobial properties [32,33]. P. glabra also exhibited good MIC values against Gram-negative bacteria (6.25$12.5 \mathrm{mg} / \mathrm{ml}$ ) and Gram-negative bacteria Pseudomonas aeruginosa $(25 \mathrm{mg} / \mathrm{ml})$, but failed to inhibit the growth of Escherichia coli and Klebsiella pneumoniae. On the other hand, $P$. parvifolia had inhibitory activity against both the Gram-negative bacteria and Gram-negative bacteria, and the MIC values were ranged from $12.5-50 \mathrm{mg} / \mathrm{ml}$.

The results of the antifungal screening are presented in Table 7. Among the plants tested, P. fruticosa and $P$. parvifolia displayed the best activity against Candida albicans with MIC value of $0.78 \mathrm{mg} / \mathrm{ml}$, followed by P. parvifolia $(1.56 \mathrm{mg} / \mathrm{ml})$.

\section{Antifungal activities against plant pathogenic fungi}

Leaf extracts of three Potentilla species had been studied for their preliminary antifungal activities against 20 plant pathogenic fungi (Table 8). By this procedure, five pathogenic fungi (Alternaria alternata, Alternaria brassicae, Glomerella cingnlata, Physalospora piricola and Venturia pyrina), with inhibition percentage over 50\%, were chosen for further analysis. Leaf extracts of Potentilla showed various degrees of inhibition against the fungi tested (Table 9). P. parvifolia exhibited the strongest inhibition for Alternaria alternata, Glomerella cingnlata, 
Table 7 Minimal inhibitory concentration (MIC) values of three Potentilla leaf extracts

\begin{tabular}{|c|c|c|c|c|}
\hline \multirow{2}{*}{$\begin{array}{c}\text { Micro-organisms } \\
\text { Bacteria }\end{array}$} & \multicolumn{4}{|c|}{ Tested materials (MIC mg/mL) } \\
\hline & P. fruticosa & P. glabra & P. parvifolia & Standard* \\
\hline Staphylococcus aureus (ATCC No. 6538) & 6.25 & 6.25 & 12.5 & 0.002 \\
\hline Enterococcus faecalis (ATCC No. 29212) & 6.25 & 12.5 & 50 & 0.03 \\
\hline Bacillus subtilis (ATCC No. 6633) & 6.25 & 12.5 & 12.5 & 0.002 \\
\hline Escherichia coli (ATCC No. 25922) & $>100$ & $>100$ & 50 & $>10$ \\
\hline Klebsiella pneumoniae (CMCC No. 46117) & $>100$ & $>100$ & 50 & $>10$ \\
\hline Pseudomonas aeruginosa (ATCC No. 27853) & 6.25 & 25 & 12.5 & $>10$ \\
\hline \multicolumn{5}{|l|}{ Fungi } \\
\hline Candida albicans (ATCC No. 10231) & 0.78 & 1.56 & 0.78 & $>10$ \\
\hline
\end{tabular}

* Standard: Benzylpenicillin was used as standard antibiotic.

Physalospora piricola and Venturia pyrina with the $\mathrm{EC}_{50}$ values of $42.56 \pm 0.20,25.71 \pm 1.16,47.02 \pm 1.86$ and $37.29 \pm 0.49 \mathrm{mg} / \mathrm{mL}$, it showed significant difference with P. fruticosa and P. glabra $(\mathrm{P}<0.05)$. P. fruticosa showed the strongest antifungal activity on Alternaria brassicae $\left(\mathrm{EC}_{50}\right.$ value $\left.=15.60 \pm 1.88 \mathrm{mg} / \mathrm{mL}\right)$, there was no significant difference $(\mathrm{P}>0.05)$ among the three leaf extracts

\section{Table 8 Preliminary antifungal activity of three Potentilla leaf extracts (concentration used $50 \mathrm{mg} / \mathrm{mL}$ ) against 20 plant pathogenic fungi}

\begin{tabular}{|c|c|c|c|}
\hline \multirow[t]{2}{*}{ Pathogenic fungi } & \multicolumn{3}{|c|}{ Inhibiting rate $/ \%$} \\
\hline & P. fruticosa & P. glabra & P. parvifolia \\
\hline Alternaria alternata & $50.91 \pm 0.15^{a}$ & $50.91 \pm 0.36^{\mathrm{a}}$ & $56.36 \pm 0.00^{a}$ \\
\hline Alternaria brassicae & $60.87 \pm 3.26^{a}$ & $63.04 \pm 3.77^{\mathrm{a}}$ & $56.52 \pm 3.77^{\mathrm{a}}$ \\
\hline Alternaria solani & $49.18 \pm 2.84^{b}$ & $47.54 \pm 2.64^{b}$ & $39.34 \pm 2.18^{a}$ \\
\hline Bipolaris sorokininan & $49.09 \pm 3.15^{c}$ & $25.45 \pm 3.63^{\mathrm{a}}$ & $36.36 \pm 3.15^{b}$ \\
\hline Botrytis cinerrea & ND & ND & ND \\
\hline Cladosporium fulvum & $35.48 \pm 2.79^{a}$ & $43.55 \pm 2.79^{b}$ & $50.81 \pm 1.40^{c}$ \\
\hline Colletotrichum gloeosporioides & $54.55 \pm 3.15^{c}$ & $41.82 \pm 3.21^{b}$ & $32.73 \pm 2.82^{a}$ \\
\hline Verticillium dahliaee & $54.72 \pm 2.83^{b}$ & $33.96 \pm 3.27^{\mathrm{a}}$ & $32.08 \pm 0.01^{a}$ \\
\hline Dothiorella gregaria & $28.00 \pm 0.01^{\mathrm{a}}$ & $32.00 \pm 3.46^{\mathrm{a}}$ & $28.00 \pm 0.01^{\mathrm{a}}$ \\
\hline Fusarium oxysporum & $42.11 \pm 3.26^{b}$ & $47.37 \pm 0.04^{b}$ & $33.33 \pm 3.04^{\mathrm{a}}$ \\
\hline Glomerella cingnlata & $61.76 \pm 2.94^{b}$ & $52.94 \pm 1.88^{\mathrm{a}}$ & $52.94 \pm 0.07^{\mathrm{a}}$ \\
\hline Phacidiopycnis washingtonensis & $46.55 \pm 2.99^{c}$ & $37.93 \pm 0.00^{a}$ & $43.10 \pm 0.03^{b}$ \\
\hline Physalospora piricola & $55.88 \pm 2.94^{\mathrm{a}}$ & $56.67 \pm 2.38^{a}$ & $56.86 \pm 3.40^{a}$ \\
\hline Piricularia oryzae & $36.96 \pm 3.77^{b}$ & $23.91 \pm 3.17^{\mathrm{a}}$ & $30.43 \pm 3.76^{a b}$ \\
\hline Rhizoctonia cerealis & $25.20 \pm 3.02^{a}$ & $26.80 \pm 2.08^{a}$ & $25.20 \pm 2.50^{\mathrm{a}}$ \\
\hline Sclerotinia cerealis & ND & $7.27 \pm 2.46^{\mathrm{a}}$ & $11.36 \pm 0.62^{b}$ \\
\hline Thanatephorus cucumeris & $62.07 \pm 1.98^{c}$ & $36.21 \pm 2.99^{a}$ & $50.86 \pm 2.59^{b}$ \\
\hline Valsa mali & $43.64 \pm 3.15^{b}$ & $32.73 \pm 3.15^{a}$ & $45.45 \pm 1.45^{b}$ \\
\hline Venturia pyrina & $56.00 \pm 3.46^{b}$ & $54.00 \pm 1.73^{a}$ & $66.00 \pm 3.46^{c}$ \\
\hline Verticillium dahliae & $40.74 \pm 3.21^{c}$ & $25.93 \pm 3.21^{a}$ & $33.33 \pm 0.01^{b}$ \\
\hline
\end{tabular}

Each values represented in tables are means $\pm S D(N=3)$.

Values with different letters $(a, b, c)$ within same row are significantly different $(P<0.05)$.

ND: not determined at tested concentrations. for Alternaria brassicae. In total, P. parvifolia displayed higher antifungal activity against all the 5 fungi tested, followed by P. fruticosa and P. glabra.

It is generally accepted that phenolic compounds present in plant extracts play an important role in their antimicrobial effects, and several studies claim that rutin, ellagic acid and hyperoside exhibit potent antimicrobial activity $[25,33,34]$. While the leaf extracts of $P$. parvifolia showed the highest content of analyzed phenolic compounds and largest peak numbers, this may be the reason for its high antifungal activity.

\section{Conclusions}

Variation in phytochemical profiles, antioxidant and antimicrobial activities of three species of Potentilla are reported. The leaf extracts contributed 55.22$84.93 \mathrm{mmol}$ equiv. GAE/100 $\mathrm{g}$ of total phenolic content and 41.87-84.14 mmol equiv. QUE/100 g of total flavonoid content. There were 11 common peaks which were detected in all leaf extracts by RP-HPLC assay. Moreover, six compounds $((+)$-catechin, caffeic acid, ferulic acid, hyperoside, rutin and ellagic acid) were detected and quantified. Hyperoside was the predominant phenolic acid found in Potentilla species analysed (2.56$8.86 \mathrm{mg} / \mathrm{g})$. It showed that significant differences in

Table $9 \mathrm{EC}_{50}$ values of three Potentilla leaf extracts against five selected plant pathogenic fungi

\begin{tabular}{ccccc}
\hline Pathogenic fungi & \multicolumn{4}{c}{$\mathrm{EC}_{\mathbf{5 0}}$ value $(\mathrm{mg} / \mathrm{mL})$} \\
\cline { 2 - 5 } & $\boldsymbol{P}$. fruticosa & P. glabra & P. parvifolia & Standard* \\
\hline Alternaria alternata & $46.04 \pm 1.68^{c}$ & $47.79 \pm 1.64^{c}$ & $37.29 \pm 0.49^{b}$ & $0.43 \pm 0.03^{\mathrm{a}}$ \\
Alternaria brassicae & $15.60 \pm 1.88^{b}$ & $20.34 \pm 2.55^{\mathrm{b}}$ & $20.52 \pm 1.49^{\mathrm{b}}$ & $0.06 \pm 0.02^{\mathrm{a}}$ \\
Glomerella cingnlata & $47.89 \pm 0.30^{c}$ & $48.27 \pm 0.07^{c}$ & $42.56 \pm 0.20^{\mathrm{b}}$ & $0.03 \pm 0.01^{\mathrm{a}}$ \\
Physalospora piricola & $54.98 \pm 2.13^{c}$ & $63.28 \pm 2.12^{\mathrm{d}}$ & $47.02 \pm 1.86^{\mathrm{b}}$ & $0.48 \pm 0.01^{\mathrm{a}}$ \\
Venturia pyrina & $33.46 \pm 1.39^{c}$ & $35.32 \pm 0.46^{c}$ & $25.71 \pm 1.16^{\mathrm{b}}$ & $0.42 \pm 0.01^{\mathrm{a}}$
\end{tabular}

*Standard: Amphotericin was used as standard antibiotic. Each values represented in tables are means $\pm \mathrm{SD}(\mathrm{N}=3)$ Values with different letters $(a, b, c, d)$ within same row are significantly different $(\mathrm{P}<0.05)$. 
phytochemical content can exist among Potentilla species. Moreover, this analysis of chromatograms provides a highly rational approach to the authentication and quality assessment of three Potentilla species through these characteristic peaks. The antioxidant activity was assessed using the DPPH, ABTS ${ }^{+}$and FRAP assays. $P$. fruticosa possessed the highest antioxidant capacity with the $\mathrm{DPPH}_{\mathrm{IC} 50}, \mathrm{ABTS}$ and FRAP values of $16.87 \mu \mathrm{g} / \mathrm{mL}$, 2763.48 and $1398.70 \mu \mathrm{mol}$ Trolox equivalent/g, respectively. This work has shown that the phytochemicals present in Potentilla species have potent antioxidant activity and that the free radical scavenging capacity (DPPH and ABTS radical scavenging assays) in Potentilla species is positively correlated with total phenolic content. Additionally, $P$. fruticosa showed the best activity against the Gram-negative bacteria $(6.25 \mathrm{mg} / \mathrm{mL})$, Gram-negative bacteria Pseudomonas aeruginosa $(6.25 \mathrm{mg} / \mathrm{mL})$ and fungus Candida albicans $(0.78 \mathrm{mg} / \mathrm{mL})$, but failed to inhibit the growth of Escherichia coli and Klebsiella pneumoniae. P. glabra showed the same property as P. fruticosa. While $P$. parvifolia possessed inhibitory activity against all the selected microorganisms $(0.78-50 \mathrm{mg} / \mathrm{mL})$. P. parvifolia also showed the strongest inhibitions for the selected plant pathogenic fungi, this was suspected to be associated with its highest total content of six phenolic compounds $(14.17 \mathrm{mg} / \mathrm{g})$ as well as the richest peak numbers (15 peaks) or any other phytochemicals we had not detected. Despite ongoing scientific research on this species, this study constitutes the first attempt at comparing the phytochemical composition as well as the antioxidant and antimicrobial activities of three Potentilla leaf extracts. However, these compounds were only described for a limited number of Potentilla species. This genus and its quantification of phyto-constituents as well as pharmacological profile based on in vitro, in vivo studies and on clinical trials should be further investigated.

\section{Competing interests}

The authors declare that they have no competing interests.

\section{Authors' contributions \\ S-sW was responsible for the experiments and acquisition of data, analysis, drafting of the manuscript. D-mW was coordinator and designed all the as- says. W-jP performed the investigation of phytochemical profiles experi- ments. D-wL made contribution to collection and preparation of herbal samples. All authors read and approved the final manuscript.}

\section{Acknowledgements}

This work was supported by the program from the Fundamental Research Funds for the Central Universities (ZD2013010).

Received: 5 September 2013 Accepted: 15 November 2013 Published: 19 November 2013

\section{References}

1. Eriksson T, Donoghue MJ, Hibbs MS: Phylogenetic analysis of Potentilla using DNA sequences of nuclear ribosomal internal transcribed spacers (ITS), and implications for the classification of Rosoideae (Rosaceae). Plant Syst Evol 1998, 211:155-179.
2. Tomczyk M, Paduch R, Wiater A, Pleszczyńska M, Kandefer-szersze M, Szczodrak J: The influence of aqueous extracts of selected potentilla species on normal human colon cells. Acta Pol Pharm - Drug Research 2013, 70:523-531.

3. Gürbüz I, Özkan AM, Yesilada E, Kutsal O: Anti-ulcerogenic activity of some plants used in folk medicine of Pinarbasi (Kayseri, Turkey). J Ethnopharmacol 2005, 101:313-318.

4. Leporatti ML, Ivancheva S: Preliminary comparative analysis of medicinal plants used in the traditional medicine of Bulgaria and Italy. J Ethnopharmacol 2003, 87:123-142.

5. Miliauskas G, van Beek TA, Venskutonis PR, Linssen JP, de Waard P, Sudhölter EJ: Antioxidant activity of Potentilla fruticosa. J Sci Food Agric 2004, 84:1997-2009.

6. Syiem D, Syngai G, Khup P, Khongwir B, Kharbuli B, Kayang H: Hypoglycemic effects of Potentilla fulgens L. in normal and alloxaninduced diabetic mice. J Ethnopharmacol 2002, 83:55-61.

7. Shushunov S, Balashov L, Kravtsova A, Krasnogorsky I, Latté KP, Vasiliev A: Determination of acute toxicity of the aqueous extract of Potentilla erecta (Tormentil) rhizomes in rats and mice. J Med Food 2009, 12:1173-1176.

8. Tomczyk M, Pleszczyńska M, Wiater A: Variation in total polyphenolics contents of aerial parts of Potentilla species and their anticariogenic activity. Molecules 2010, 15:4639-4651.

9. Zhao Y-L, Cai G-M, Hong X, Shan L-M, Xiao X-H: Anti-hepatitis B virus activities of triterpenoid saponin compound from Potentilla anserine L. Phytomedicine 2008, 15:253-258.

10. Tomczyk M, Latté KP: Potentilla-A review of its phytochemical and pharmacological profile. J Ethnopharmacol 2009, 122:184-204.

11. Tomczyk M: Secondary metabolites from Potentilla recta L. and Drymocallis rupestris (L.) Soják (syn. Potentilla rupestris L.)(Rosaceae). Biochem Syst Ecol 2011, 39:893-896.

12. Barkley T, Cronquist A: A Synonymized Checklist of the Vascular Flora of the United States, Canada and Greenland. Volume II, The Biota of North America. Brittonia 1980, 32(4):573-573.

13. Shimono A, Ueno S, Gu S, Zhao X, Tsumura Y, Tang Y: Range shifts of Potentilla fruticosa on the Qinghai-Tibetan Plateau during glacial and interglacial periods revealed by chloroplast DNA sequence variation. Heredity 2009, 104:534-542

14. Mitich L: Cinquefoils (Potentilla spp.): the five finger weeds. Weed Technology 1995, 9:857-861.

15. Miliauskas $G$, Venskutonis $P$, Van Beek $T$ : Screening of radical scavenging activity of some medicinal and aromatic plant extracts. Food Chem 2004, 85:231-237

16. Nkiliza J: Process for extracting catechin polyphenols from potentillas, extract obtained and its use. In Book Process for extracting catechin polyphenols from potentillas, extract obtained and its use.1999. (Editor ed. eds.). City: US Patent 5,928,646.

17. Wang LY, Ikeda H, Liu TL, Wang YJ, Liu JQ: Repeated Range Expansion and Glacial Endurance of Potentilla glabra (Rosaceae) in the Qinghai-Tibetan Plateau. J Integr Plant Biol 2009, 51:698-706.

18. Wang L-Y, Kou Y-X, Wu G-L, Wang Y-J: Development and characterization of novel microsatellite markers isolated from Potentilla fruticosa $\mathrm{L}$. (Rosaceae), and cross-species amplification in its sister species-Potentilla glabra L. Conserv Genet Resour 2009, 1:51-53.

19. Davidson CG, Lenz LM: Experimental taxonomy of Potentilla fruticosa. Can J Bot 1989, 67:3520-3528.

20. Yang J, Martinson TE, Liu RH: Phytochemical profiles and antioxidant activities of wine grapes. Food Chem 2009, 116:332-339.

21. Duncan CE, Gorbet DW, Talcott ST: Phytochemical content and antioxidant capacity of water-soluble isolates from peanuts (Arachis hypogaea L.). Food Res Int 2006, 39:898-904

22. Singleton V, Rossi JA: Colorimetry of total phenolics with phosphomolybdicphosphotungstic acid reagents. Am J Enol Viticul 1965, 16:144-158.

23. He X, Liu D, Liu RH: Sodium borohydride/chloranil-based assay for quantifying total flavonoids. J Agric Food Chem 2008, 56:9337-9344.

24. Yen $\mathrm{G}-\mathrm{C}$, Chen $\mathrm{H}-\mathrm{Y}$ : Antioxidant activity of various tea extracts in relation to their antimutagenicity. J Agric Food Chem 1995, 43:27-32.

25. Re R, Pellegrini N, Proteggente A, Pannala A, Yang M, Rice-Evans C: Antioxidant activity applying an improved ABTS radical cation decolorization assay. Free Radical Bio Med 1999, 26:1231-1237.

26. Benzie IF, Strain J: The ferric reducing ability of plasma (FRAP) as a measure of "antioxidant power": the FRAP assay. Anal Biochem 1996, 239:70-76. 
27. Bansod S, Rai M: Antifungal activity of essential oils from Indian medicinal plants against human pathogenic Aspergillus fumigatus and A. niger. World J Med Sci 2008, 3(2):81-88.

28. Hsu F-L, Chen P-S, Chang H-T, Chang S-T: Effects of alkyl chain length of gallates on their antifungal property and potency as an environmentally benign preservative against wood-decay fungi. Int Biodeter Biodegr 2009, 63(5):543-547.

29. Tian J, Ban X, Zeng H, He J, Huang B, Wang Y: Chemical composition and antifungal activity of essential oil from Cicuta virosa $L$. var. latisecta Celak. Int J Food Microbiol 2011, 145(2):464-470.

30. Falleh H, Ksouri R, Chaieb K, Karray-Bouraoui N, Trabelsi N, Boulaaba M, Abdelly C: Phenolic composition of Cynara cardunculus L. organs, and their biological activities. C R Biol 2008, 331:372-379.

31. Tomczyk M, Leszczyńska K, Jakoniuk P: Antimicrobial activity of Potentilla species. Fitoterapia 2008, 79(7):592-594.

32. Chandrasekaran $\mathrm{M}$, Venkatesalu V: Antibacterial and antifungal activity of Syzygium jambolanum seeds. J Ethnopharmacol 2004, 91(1):105-108

33. Martini S, D'Addario C, Colacevich A, Focardi S, Borghini F, Santucci A, Figura N, Rossi C: Antimicrobial activity against Helicobacter pylori strains and antioxidant properties of blackberry leaves (Rubus ulmifolius) and isolated compounds. Int J Antimicrob Agents 2009, 34(1):50-59.

34. Orhan I, Özçelik B, Kartal M, Özdeveci B, Duman H: HPLC quantification of vitexine-2'-O-rhamnoside and hyperoside in three Crataegus species and their antimicrobial and antiviral activities. Chromatographia 2007, 66(1):153-157.

doi:10.1186/1472-6882-13-321

Cite this article as: Wang et al:: Phytochemical profiles, antioxidant and antimicrobial activities of three Potentilla species. BMC Complementary and Alternative Medicine 2013 13:321.

\section{Submit your next manuscript to BioMed Central and take full advantage of:}

- Convenient online submission

- Thorough peer review

- No space constraints or color figure charges

- Immediate publication on acceptance

- Inclusion in PubMed, CAS, Scopus and Google Scholar

- Research which is freely available for redistribution 